\title{
Bacteria and tumours: causative agents or opportunistic inhabitants?
}

\author{
Joanne Cummins and Mark Tangney*
}

\begin{abstract}
Associations between different bacteria and various tumours have been reported in patients for decades. Studies involving characterisation of bacteria within tumour tissues have traditionally been in the context of tumourigenesis as a result of bacterial presence within healthy tissues, and in general, dogma holds that such bacteria are causative agents of malignancy (directly or indirectly). While evidence suggests that this may be the case for certain tumour types and bacterial species, it is plausible that in many cases, clinical observations of bacteria within tumours arise from spontaneous infection of established tumours. Indeed, growth of bacteria specifically within tumours following deliberate systemic administration has been demonstrated for numerous bacterial species at preclinical and clinical levels. We present the available data on links between bacteria and tumours, and propose that besides the few instances in which pathogens are playing a pathogenic role in cancer, in many instances, the prevalent relationship between solid tumours and bacteria is opportunistic rather than causative, and discuss opportunities for exploiting tumour-specific bacterial growth for cancer treatment.
\end{abstract}

\section{Introduction}

The development of cancer is associated with several genetic and environmental factors. Furthermore there has been an association between the development of cancer and bacterial and viral infections for decades. Several viruses can integrate into the human genome and directly initiate tumourigenesis, such as human papillomavirus (HPV) in cervical cancer and herpesvirus in Kaposi's sarcoma [1,2]. In other cases, the development of cancer is indirect, such as with Helicobacter pylori, which contributes to both gastric cancer and mucosa-associated lymphoid tissue (MALT) lymphoma due to chronic inflammation caused by the bacteria $[3,4]$. This notwithstanding, observations made in the course of numerous studies have reported different indigenous bacterial species being isolated from infected lesions in patients (Table 1) [5,6]. As early as 1868 Bush reported 2 patients with sarcoma that had been infected with Streptococcus and Coley also detected the presence of $S$. pyogenes in a patient suffering from neck cancer $[7,8]$. In 1907 Fibiger discovered that the parasitic nematode (Spiroptera neoplastica) was associated with cancer

\footnotetext{
* Correspondence: m.tangney@ucc.ie

Cork Cancer Research Centre, BioSciences Institute, University College Cork, Cork, Ireland
}

development in rats, while it was later found that the development of cancer was associated with a vitamin A deficiency he paved the way for future discoveries in cancer causing bacteria and viruses [9]. In 1911 Francis Peyton Rous was the first to discover that cancer could be transmitted by a virus (later known as Rous sarcoma virus), but it wasn't until years later that his results were accepted by the scientific community [10,11]. In 1926 Glover stated that certain bacteria were consistently isolated from neoplastic tissue [12]. Furthermore between the years of 1936-1955 several different publications all reported the presence of microbes in cancer tissue [13-15]. More recently, it has been shown that bacteria are naturally capable of homing to tumours when systemically administered, resulting in high levels of replication locally [16]. This was originally established following IV administration of species of Clostridium, and in more recent years with numerous bacterial species, including, Salmonella, Bifidobacterium, Escherichia coli, Vibrio cholerae and Listeria monocytogenes. Furthermore, various clinical trials have shown the ability of different bacterial strains to home to and replicate specifically within tumours [17-19].

The presence of bacteria within tumours could be due to infection via the vasculature and their ability to survive and grow due to the presence of nutrients within 
Table 1 Overview of bacteria identified in different tumour types

\begin{tabular}{lll}
\hline Cancer & Cancer role & Reference \\
\hline Lung cancer & & \\
\hline Streptococcus mitis & Prevalent & {$[20]$} \\
\hline Staphylococcus epidermis & Prevalent & {$[20]$} \\
\hline Bacillus sp. & Prevalent & {$[20]$} \\
\hline Mycoplasma sp. & Causative & {$[20,21]$} \\
\hline Chlamydophila pneumonia & Causative & {$[22]$} \\
\hline
\end{tabular}

\begin{tabular}{lll}
\hline Pancreatic cancer & & \\
\hline Robinsoniella peoriensis & Prevalent & {$[23]$} \\
\hline Pedioccoccus acidilactici & Prevalent & {$[24]$} \\
\hline Leuconostoc lactis & Prevalent & {$[24]$} \\
\hline L. mesenteroides & Prevalent & {$[24]$} \\
\hline
\end{tabular}

\begin{tabular}{lll}
\hline Breast cancer & & \\
\hline Staphylococcus epidermidis & Prevalent & {$[25]$} \\
\hline Mycoplasma sp. & Prevalent & {$[21]$} \\
\hline Oral cancer & & \\
\hline Ralstonia insidiosa & Prevalent & {$[26]$} \\
\hline Fusobacterium naviforme & Prevalent & {$[26]$} \\
\hline Prevotella sp. & Prevalent & {$[26]$} \\
\hline Gall-bladder carcinoma & & \\
\hline Salmonella typhi & Causative & {$[27]$} \\
\hline H. pylori & Causative & {$[28]$} \\
\hline H. hepaticus & Causative & {$[28]$} \\
\hline H. bilis & Causative & {$[29]$} \\
\hline
\end{tabular}

Pulmonary Mucosa-Associated lymphoid tissue (MALT) lymphoma

\begin{tabular}{lll}
\hline Chlamydia pneumonia & Causative & {$[30]$} \\
\hline C. trachomatis & Causative & {$[30]$} \\
\hline C. psittaci & Causative & {$[30]$} \\
\hline Ocular Adenexa MALT lymphoma &
\end{tabular}

\begin{tabular}{lll}
\hline C. psittaci & Causative & {$[31]$} \\
\hline Ovarian cancer & & \\
\hline Chlamydia trachomatis & Prevalent & {$[32]$} \\
\hline Mycoplasma sp. & Causative & {$[33]$} \\
\hline Mycoplasma sp. & Causative & {$[21]$} \\
\hline Colorectal cancer & & \\
\hline Streptococcus gallolyticus & Causative & {$[34]$} \\
\hline Fusobacterium nucleatum & Prevalent (?) & {$[35,36]$} \\
\hline F. necrophorum & Prevalent & {$[36,37]$} \\
\hline F. mortiferum & Prevalent & {$[36]$} \\
\hline F. perfoetens & Prevalent & {$[36]$} \\
\hline Roseburia sp. & Prevalent & {$[37]$} \\
\hline Faecalibacterium sp. & Prevalent & {$[37]$} \\
\hline Escherichia coli & Prevalent & {$[38]$} \\
\hline Citrobacter sp. & Prevalent & {$[38]$} \\
\hline H. pylori & Causative & {$[39]$} \\
\hline Mycoplasma sp. & Prevalent & {$[21]$} \\
\hline
\end{tabular}


in $2.5-15 \%$ of individuals [47-49]. One theory for the association between $S$. bovis/gallolyticus and CRC is due the increased load of S. bovis/gallolyticus in the colon, which has been shown to be associated with inflammatory bowel disease or malignant/premalignant lesions of the tumour. From the research preformed to date it is believed that S. bovis/gallolyticus association with CRC seems to be of etiological nature and the proposed carcinogenic potential of S. bovis/gallolyticus is most likely a propagation factor for premalignant tissues. The early detection of CRC via identification of S. bovis/gallolyticus DNA or antibodies may be a potential screening method for at high-risk groups [50].

C. pneumoniae is a Gram-negative bacillus and an obligate intracellular parasite that causes respiratory infections in over $50 \%$ of adults. The relationship between $C$. pneumoniae and lung cancer has been studied for over 10 years by clinical and laboratory research methods but the results have been inconsistent. Recently a meta-analysis approach was used to analyse previously published data [51]. They concluded a dose-response effect in which increasing lung cancer risk was associated with increasing IgA (serological criteria for chronic infection) antibody titre, also suggested that higher titre may be a better predictor of lung cancer risk than lower antibody titres [51]. All these studies also indicated that C. pneumoniae infection was associated with increased risk of lung cancer in certain sub-groups such as young individuals, men, former smokers and for squamous cell carcinomas or small cell carcinomas [22,51-55].

\section{The other side of the coin: opportunistic infections of established tumours}

While bacterial presence in certain tumours is associated with the development of that cancer, in many cases, bacteria present in tumours may reflect local infections of existing malignant tissue [56]. Observations made in the course of numerous studies have reported different indigenous bacterial species being isolated from infected lesions in patients (Table 1). After Bush's report of Streptococcus in sarcomas in 1868 [7], William Coley, the "father of immunotherapy", identified the presence of S. pyogenes in soft tissue sarcoma, and was one of the first to characterise concomitant infection of tumours and how this could lead to remission of incurable neoplastic malignancy $[57,58]$. In recent years there have been a number of studies that show a correlation between bacterial infection and tumour regression. Ruckdeschel et al. found that patients who developed empyema after lung cancer had a significantly improved survival rate after 5 years compared with uninfected patients (50\% v's $18 \%$ ) [59]. Furthermore, two patients with malignant CNS tumours unexpectedly regressed after infection. Of these patients, one of the infections was viral in nature while the second was found to feature Corynebacterium hemolyticum and Staphylococcus epidermidis. The patient survived for 9 years after his tumour was originally discovered [60]. A recent study to determine the survival rate after infection in glioblastoma multiforme patients demonstrated no survival advantage in patients with post-operative infection but they did find that the deep infection subgroup showed a trend towards increased survival [61]. Bohman and colleagues literature search revealed 9 patients with malignant intracranial tumours who experienced prolonged survival due to infection with a mean survival of 7.5-8 years and no evidence of central nervous system recurrence upon death. The majority of patients had infections with either S. aureus or Enterobacter aerogens [61].

\section{Mechanisms of bacterial replication within tumours}

There are several proposed factors involved in how bacteria replicate and survive within tumours. Traditionally, the main mechanism is thought to be due to the hypoxic nature of many solid tumours, which results in low oxygen levels compared with normal tissues, providing a unique growth environment for anaerobic and facultative anaerobic bacteria [62]. Other factors contributing to bacterial replication in the tumour include the presence of bacterial nutrients within the necrotic region such as purines [63]. Furthermore, the involvement of bacterial chemotaxis towards chemo-attractant compounds present in necrotic regions (e.g. aspartate, serine, citrate, ribose or galactose) produced by quiescent cancer cells has also been suggested as a contributing factor [63].

As knowledge in the field grows, elements believed to be key for tumour-specific bacterial replication include aberrant neovasculature and local immune suppression [63]. As tumours develop, they promote the construction of new blood vessels (neo-angiogenesis). However, these newly formed vessels are highly disorganized with incomplete endothelial linings and blind ends, resulting in 'leaky' blood vessels and slow blood flow. This leaky tumour vasculature may allow circulating bacteria to enter tumour tissue, and embed locally (Figure 1) [63]. Furthermore, a variety of mechanisms are employed by cancerous cells to avoid recognition by the immune system resulting in insufficient immune activity within tumours, potentially providing a refuge for bacteria to evade immune clearance, not present elsewhere in the body $[64,65]$.

\section{Systemic microbes: routes of infection}

While blood is taken to be free of bacteria in healthy individuals, it is plausible that establishment of a tumour infection might occur even with extremely low numbers of viable bacteria, given the phenomenon of tumourspecific bacterial growth. This hypothesis suggests the tumour providing a localized 'amplified read-out' for 


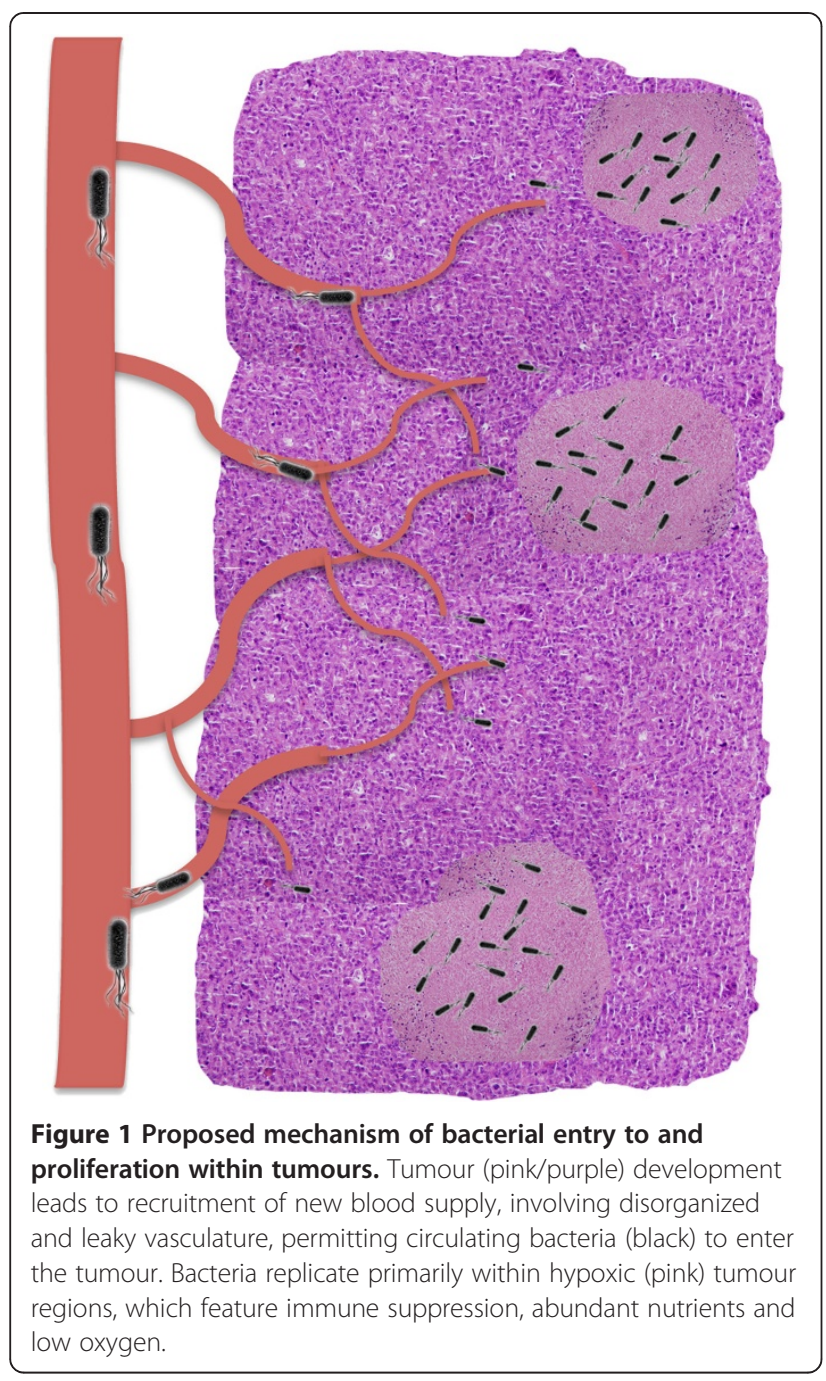

bacterial infection, which is otherwise unapparent. Presence of bacteria in the blood stream may be due to wound infection (e.g. post surgery), or bacterial translocation (BT) from the gastrointestinal tract (GIT).

\section{GIT translocation}

BT is the invasion of indigenous intestinal bacteria through the gut mucosa into normal sterile tissue [66]. The means by which bacteria translocate is thought to be by two distinct pathways of gastrointestinal permeability: (1) transcellular through the enterocytes and (2) paracellular using tight junctions [67]. There are also thought to be two major methods by which bacterial compounds gain access to systemic circulation; (1) through the enteric venous system to the portal vein and (2) following lymphatic drainage. After much analysis it is thought that the lymphatic route is the primary pathway of translocation [67]. Experimental and clinical studies have detected both indigenous and non-indigenous bacteria within the mesenteric lymph node (MLN). Some studies have demonstrated that BT from the gut to the MLN is quiet common, with it occurring in 4-59\% of patients [67]. Furthermore patients needing surgery for abdominal infection fared much worse if the MLN was infected with non-indigenous bacteria [67]. In normal healthy individuals, the normal immune response will destroy bacteria associated with BT by phagocytosis. However, immunocompromised individuals have a higher risk of being affected by BT. Cannon et al., found that one of the main underlying conditions increasing patients susceptibility to BT associated bacteraemia was cancer [68]. Penn and colleagues demonstrated an increased translocation from the GIT of S-180 tumour-bearing mice, leading them to postulate that the immune deficiencies associated with tumour growth may be adequate to allow the viable bacteria to translocate from the GIT to the developing tumour [69]. Our group has shown that oral administration of non-pathogenic bacteria to mice results in trafficking from the GIT with subsequent homing to and replication specifically in tumours [70].

The ability of microorganisms to translocate, survive, and proliferate in extra-intestinal tissues involves complex interactions between the host defence mechanisms and the bacterium's ability to invade host tissues. Although the importance of host immune function and the bacterium's intestinal population size have been implicated as significant contributory factors, the precise mechanisms involved remains unknown $[5,66,69,71]$.

\section{The oral microbiome}

As described earlier, members of the oral microbiota have been associated with pancreatic cancer [72,73]. Farrell and colleagues carried out microbial profiling using the Human Oral Microbe Identification Microarray (HOMIM) to compare the salivary microbiota between 10 pancreatic cancer patients and 10 normal matched healthy controls [72]. In their study they found that the levels of Neisseria elongata and Streptococcus mitis were decreased in the cancer patients relative to healthy controls and the level of Granulicaetella adiacens was increased in the cancer patients. These results validate a link between $N$. elongata and G. adiacens with periodontal disease, which has been linked to an increased risk of pancreatic cancer [72]. Farrell et al., postulated that as G. adiacens, an opportunistic pathogen, may be associated with systemic inflammation and an elevation in this bacteria could be related to the decreased levels of S. mitis [72]. Furthermore $S$. mitis plays a protective role against the adhesion of carcinogenic bacteria and the loss of $S$. mitis may contribute to aggressive periodontitis. Whether the variation in oral bacteria in pancreatic cancer is causative rather than reactive would have to be investigated further to determine how local oral bacteria without entering the blood stream could potentially cause systemic diseases, 
chronic inflammation and neoplasia [72]. In the case of periodontal bacteria, such as Porphyromonas gingivalis it is believed that lymph vessel openings trap bacteria en route from the mouth to the blood stream and then carry them to the vein of the venous angle near the supraclavicular area [74]. A previous study by Sakamoto and colleagues analysed the regional lymph nodes of 30 patients with oral cancer [75]. A total of 153 lymph nodes were harvested for microbiological examination. It was found that viable bacteria were found in $45 \%$ of the lymph nodes from $83 \%$ of patients. The cervical lymph nodes are in contact with the lymphatic flow before returning to the thoracic duct. The presence of viable bacteria, mainly oral streptococcus, in these lymph nodes supports the hypothesis of the association between oral mucosal damage and bacterial invasion into general circulation [75]. Furthermore the anaerobic bacteria detected (Peptostreptococcus) in the lymph nodes have been detected in gastrointestinal tumour tissue suggesting that the oral mucosal defect could promote translocation of anaerobes into the regional nodes $[75,76]$.

Farrell and colleagues then evaluated the specificity of the microbial biomarkers against another HOMIM microbial study that had been performed on lung cancer. They observed that none of the bacterial biomarkers validated in their study was significantly altered in the microflora profile of lung cancer [72]. This validates that the microbial biomarkers present in the saliva are specific for pancreatic cancer.

\section{Fusobacterium}

A bacterium that of late has been linked with CRC is Fusobacterium nucleatum $[35,36]$. F. nucleatum is an invasive, adherent and pro-inflammatory anaerobe that is commonly found in dental plaque and is well known to be associated with periodontitis $[77,78,79]$. However, Fusobacterium is also known to be a gut commensal with probiotic features [79]. Castellarin and colleagues analysed the RNA sequence of 11 matched pairs of colorectal carcinoma and adjacent normal tissue and found an over-representation of $F$. nucleatum [35]. They postulated that the presence of the bacterium within the tumour could just represent an prevalent infection at an immunocompromised site or may be involved in tumourigenesis [75].

Another study using a similar method identified the presence of several Fusobacterium species in CRC, in particular F. nucleatum, F. mortiferum and F. necrophrum [36]. They believe that Fusobacterium may be following the concept of the "alpha-bug" theory -where certain members of a microbial community are capable of remodelling the microbiome as a whole to drive proinflammatory immune responses and colonic epithelial cell transformation leading to cancer [36,80]. In addition,
Fusobacterium has been associated with inflammatory bowel disease (IBD), one of the three highest risk factors for developing CRC [81]. Kostic and colleagues postulate that Fusobacterium may contribute to tumourigenesis in a limited subset of patients mainly thorough an inflammatory mediated mechanism [36].

One interesting facet of $F$. nucleatum is that it is one of the most prevalent species found in infections of the amniotic fluid and the placenta leading to pre-term birth $[82,83]$. There is also a correlation between pre-term birth and periodontal disease. During periodontal infection the quantities of periodontal pathogens increases dramatically leading to transient bacteraemia [84-86]. This can lead to selective colonization of undesired sites. The ability of $F$. nucleatum to proliferate in the placenta and eventually spread to the amniotic fluid and foetuses may in part be due to local immunosuppression in reproductive organs during pregnancy [87]. Furthermore the slow blood flow rate and low shear force in the venous sinuses of the placenta provides an opportunity for $F$. nucleatum to adhere and invade the endothelial cells [87]. As similar conditions occur within a tumour this may be a reason why F. nucleatum has been identified within CRC. Even if there is no etiological link between the bacterium and CRC the significant abundance of Fusobacterium in CRC may be used for screening purpose [35].

\section{Exploitation of opportunistic infective agents}

The ideal anti-cancer therapy would selectively eradicate tumours, whilst minimizing side effects to normal tissue. Use of bacteria to specify therapeutic agents to tumours presents an attractive strategy in this context, since we and others have shown in mice that bacteria naturally replicate specifically within tumours when systemically administered [88]. Various preclinical trials have shown the ability of different bacterial strains to traffic to tumour sites, locally produce therapeutic agents, and mediate highly effective and specific therapeutic responses. Bacterial cancer therapies to date have utilized 'laboratory' strains (e.g. Salmonella typhimurium or clostridia), and while results in murine models have been impressive, successes have failed to be replicated in patients, with the inherent pathogenicity and immunogenicity of the bacteria employed outweighing therapeutic responses in patients.

Various preclinical and clinical trials have shown the ability of different bacterial strains to selectively traffic to tumour sites, and mediate highly effective and specific therapeutic responses [63]. A wide range of gene therapy strategies exists, aiming at inducing malignant cell death, either directly (e.g. using 'suicide' genes) or indirectly, such as cancer immunotherapy approaches based on killing tumour cells through intervention of various 
effector cells of the immune system [89]. The specific nature of bacterial colonisation of tumours could be exploited to aid in cancer treatment. In the case of noninvasive bacteria, strains can be engineered to secrete therapeutic proteins locally within the tumour environment, external to tumour cells [90]. This cell therapy approach is suitable for indirectly acting therapeutic strategies such as anti-angiogenesis and immune therapy.

Angiogenesis is the formation of new capillary blood vessels from existing microvessels [63]. The antiangiogenesis strategy seeks to prevent the formation of new vessels. Gene-based anti-angiogenic therapy has been used in conjunction with other approaches to decrease angiogenesis. Bifidobacterial expression of endostatin genes, an endogenous inhibitor of angiogenesis, have shown promise in pre-clinical trials [63]. In addition Salmonella VPN2009 has been successful in mediating anti-angiogenic therapy [63]. The immune therapy approach focuses on killing the tumour cell through direct or indirect alteration of immune effector cells (i.e. $\mathrm{CD}^{+}$, T cells or NK cells). $S$. Typhimurium has been used in several murine trials examining immunotherapies, with significant tumour reduction resulting from local bacterial expression or tumour cell expression of the immune-stimulating molecules IL-18, CCL21, LIGHT or Fas ligand [63]. Preclinical studies have also used bifidobacteria in combination therapy with cytokines such as granulocyte colony-stimulating factor (GCSF), resulting in superior anti-tumour effects [63].

However, bacterial studies have largely focused on delivery of genes for subsequent tumour cell expression of anti-cancer agents utilizing pathogenic invasive bacterial species. Invasive bacteria are capable of delivering genes intracellularly with the aim of targeting bactofection to tumours. Bactofection is bacterialmediated transfer of plasmid DNA to mammalian cells and has shown potential as a method to express heterologous proteins in different mammalian cells types $[91,92]$. In bactofection the bacteria contain a plasmidbased gene for transfer to the new host cells. Delivery of genetic material is achieved through entry of the entire bacterium into the target cells. Spontaneous or induced bacterial lysis leads to release of the plasmid for future eukaryotic cell expression. Various bacterial species including Salmonella spp., L. monocytogenes, and E. coli have been examined as bactofection vectors. Salmonella is the most widely studied genus for bactofection with numerous studies demonstrating therapeutic expression and anti-tumour efficacy [63]. Preclinical trials utilising various attenuated, replication incompetent strains of salmonellae delivered by direct intratumoural or systemic administration have achieved impressive anti-tumour responses using a range of therapeutic approaches. The mechanism of DNA transfer is at present poorly understood for many species, and may depend on properties inherent to the bacteria and the cell type involved [93]. Invasive strains are pathogenic in nature and therefore invade healthy tissue (liver, spleen, MLN etc.), and safety concerns need to be addressed before such an approach becomes applicable in humans [63].

Furthermore bacteria, which replicate within tumours, can be engineered to express imaging agents, allowing detection of the bacteria and the potential tumour site [63]. Given the vital aspect of early detection for cancer treatment the potential for tumour-specific bacteria in diagnostic applications is attractive. If there is a definitive link between cancer development and bacterial infection this can be used in developing new treatment strategies for cancer. Furthermore microbes can affect the metabolism of pharmaceutical agents including those used to treat cancer. Therefore better knowledge of microbe composition and metabolic activity could improve therapeutic options.

\section{Conclusion}

The examples provided here are not comprehensive, but are rather an indication of the alternative impacts bacteria may have on different types of cancers. Screening for bacteria present in cancer tissues of various histological types may open up new dimensions in our understanding of this relationship, and its importance, if any. As high throughput deep sequencing technologies become more available, mining for bacterial strains adapted to survive within the tumour microenvironment will permit dedicated studies on this phenomenon, perhaps even leading to the characterisation of a potential 'tumour microbiome', and may also advance the development of live bacterial vectors for tumour-specific delivery of therapeutic agents.

\section{Competing interests}

The authors declare that they have no competing interests.

\section{Authors' contributions}

Both authors were involved in writing and reviewing this article. Both authors read and approved the final manuscript.

\section{Acknowledgments}

The authors wish to acknowledge support relevant to this manuscript from the Health Research Board grants HRA_POR/2012/99 and HRA_POR/2010/

138, and the European Commission Seventh Framework Program grant PIOF-GA-2009-255466.

Received: 7 November 2012 Accepted: 24 March 2013

Published: 28 March 2013

\section{References}

1. Chang $Y$, et al: Identification of herpesvirus-like DNA sequences in AIDS-associated Kaposi's sarcoma. Science 1994, 266(5192):1865-1869.

2. Huang $Y Q$, et al: Transcription of human herpesvirus-like agent (HHV-8) in Kaposi's sarcoma. J Clin Invest 1996, 97(12):2803-2806.

3. Cover TL, Blaser MJ: Helicobacter pylori in health and disease. Gastroenterology 2009, 136(6):1863-1873.

4. Polk DB, Peek RM Jr: Helicobacter pylori: gastric cancer and beyond. Nat Rev Cancer 2010, 10(6):403-414 
5. Liong MT: Safety of probiotics: translocation and infection. Nutr Rev 2008, 66(4):192-202

6. Zhou JS, et al: Acute oral toxicity and bacterial translocation studies on potentially probiotic strains of lactic acid bacteria. Food Chem Toxicol 2000, 38(2-3):153-161.

7. Busch W: Aus der Sitzung der medicinischen Section. Berlin: Klin Wochenschr; 1867:137(5).

8. Coley W: Late results of the treatment of inoperable sarcoma by the mixed toxins of Erysipelas and Bacillus prodigosus. Am J Med Sci 1906, 131:375-430.

9. Stolt CM KG, Jansson AT: An analysis of a wrong Nobel Prize-Johannes Fibiger: a study in the Nobel archives. Adv Cancer Res 2004(92):1-12.

10. Rous P: A Transmissible Avian Neoplasm (Sarcoma of the Common Fowl). J Exp Med 1910, 12(5):696-705.

11. Rous P: A Sarcoma of the Fowl Transmissible by an Agent Separable from the Tumor Cells. J Exp Med 1911, 13(4):397-411.

12. Glover T: Progress in Cancer Research. Practitioner: Canada Lancet and; 1926:67(5).

13. Crofton WM: The True Nature of Viruses. London, England: Staples Press Ltd:; 1936.

14. Livingston W-C: Neoplastic Infections of Man and Animals. Journal of the Am Med Women's Association 1953, 9(1):7-12.

15. Villesquez EJ: Le Parasitisme Latent des Cellules du Sang chez l' Homme, en Particulier dans le Sang des Cancreeux. Paris, France: Librarie Maloine; 1955.

16. Morrissey D, O'Sullivan GC, Tangney M: Tumour targeting with systemically administered bacteria. Curr Gene Ther 2010, 10(1):3-14

17. Toso JF, et al: Phase I study of the intravenous administration of attenuated Salmonella typhimurium to patients with metastatic melanoma. J Clin Oncol 2002, 20(1):142-152.

18. Nemunaitis J, et al: Pilot trial of genetically modified, attenuated Salmonella expressing the E. coli cytosine deaminase gene in refractory cancer patients. Cancer Gene Ther 2003, 10(10):737-744.

19. Heppner F, Mose JR: The liquefaction (oncolysis) of malignant gliomas by a non pathogenic Clostridium. Acta Neurochir (Wien) 1978, 42(1-2):123-125.

20. Apostolou $P$, et al: Bacterial and fungal microflora in surgically removed lung cancer samples. J Cardiothorac Surg 2011, 6:137.

21. Rogers MB: Mycoplasma and cancer: in search of the link. Oncotarget 2011, 2(4):271-273.

22. Jackson LA, et al: Association of Chlamydia pneumoniae immunoglobulin A seropositivity and risk of lung cancer. Cancer Epidemiol Biomarkers Prev 2000, 9(11):1263-1266.

23. Shen $D$, et al: Robinsoniella peoriensis bacteremia in a patient with pancreatic cancer. J Clin Microbiol 2010, 48(9):3448-3450.

24. Kikuchi $\mathrm{K}$, et al: [Microbiological and clinical studies of vancomycin resistant Leuconostoc spp. and Pediococcus spp. isolated from septicemia patients]. Kansenshogaku Zasshi 1994, 68(9):1084-1092.

25. Cantwell AR Jr, Kelso DW: Microbial findings in cancers of the breast and in their metastases to the skin. Implications for etiology. J Dermato/ Surg Oncol 1981, 7(6):483-491.

26. Hooper SJ, et al: A molecular analysis of the bacteria present within oral squamous cell carcinoma. J Med Microbiol 2007, 56(Pt 12):1651-1659.

27. Nath $G$, et al: Chronic typhoid carriage and carcinoma of the gallbladder. Eur J Cancer Prev 1997, 6(6):557-559.

28. de Martel C, et al: Helicobacter species in cancers of the gallbladder and extrahepatic biliary tract. Br J Cancer 2009, 100(1):194-199.

29. Murata $\mathrm{H}$, et al: Helicobacter bilis infection in biliary tract cancer. Aliment Pharmacol Ther 2004, 20(Suppl 1):90-94.

30. Chanudet $E$, et al: Chlamydiae and Mycoplasma infections in pulmonary MALT lymphoma. Br J Cancer 2007, 97(7):949-951.

31. Chanudet $E$, et al: Chlamydia psittaci is variably associated with ocular adnexal MALT lymphoma in different geographical regions. J Pathol 2006, 209(3):344-351.

32. Shanmughapriya $S$, et al: Viral and bacterial aetiologies of epithelial ovarian cancer. Eur J Clin Microbiol Infect Dis. 2012, 31(9):2311-2317.

33. Chan PJ, et al: Prevalence of mycoplasma conserved DNA in malignant ovarian cancer detected using sensitive PCR-ELISA. Gynecol Oncol 1996, 63(2):258-260

34. Abdulamir AS, et al: Molecular detection, quantification, and isolation of Streptococcus gallolyticus bacteria colonizing colorectal tumors: inflammation-driven potential of carcinogenesis via IL-1, COX-2, and IL-8. Mol Cancer 2010, 9:249.

35. Castellarin $\mathrm{M}$, et al: Fusobacterium nucleatum infection is prevalent in human colorectal carcinoma. Genome Res 2012, 22(2):299-306.
36. Kostic $A D$, et al: Genomic analysis identifies association of Fusobacterium with colorectal carcinoma. Genome Res 2012, 22(2):292-298.

37. Marchesi JR, et al: Towards the human colorectal cancer microbiome. PLoS One 2011, 6(5):e20447.

38. Hubbard AL, et al: Direct detection of eae-positive bacteria in human and veterinary colorectal specimens by PCR. J Clin Microbiol 1998, 36(8):2326-2330.

39. Hong SN, et al: Helicobacter Pylori Infection Increases the Risk of Colorectal Adenomas: Cross-Sectional Study and Meta-Analysis. Dig Dis Sci 2012.

40. Sedman PC, et al: The prevalence of gut translocation in humans. Gastroenterology 1994, 107(3):643-649.

41. Uemura $\mathrm{N}$, et al: Helicobacter pylori infection and the development of gastric cancer. N Engl J Med 2001, 345(11):784-789.

42. Risch HA: Pancreatic cancer: Helicobacter pylori colonization, $\mathrm{N}$-nitrosamine exposures, and ABO blood group. Mol Carcinog 2012, 51(1):109-118.

43. Fox JG, et al: Gut microbes define liver cancer risk in mice exposed to chemical and viral transgenic hepatocarcinogens. Gut 2010, 59(1):88-97.

44. Rao VP, et al: Proinflammatory CD4+ CD45RB(hi) lymphocytes promote mammary and intestinal carcinogenesis in $\mathrm{Apc}(\mathrm{Min} /+)$ mice. Cancer Res 2006, 66(1):57-61.

45. Rogers $A B$ : Distance burning: how gut microbes promote extraintestinal cancers. Gut Microbes 2011, 2(1):52-57.

46. Fox JG, et al: Helicobacter hepaticus infection in mice: models for understanding lower bowel inflammation and cancer. Mucosal Immunol 2011, 4(1):22-30

47. Burns CA, McCaughey R, Lauter CB: The association of Streptococcus bovis fecal carriage and colon neoplasia: possible relationship with polyps and their premalignant potential. Am J Gastroenterol 1985, 80(1):42-46.

48. Murray HW, Roberts RB: Streptococcus bovis bacteremia and underlying gastrointestinal disease. Arch Intern Med 1978, 138(7):1097-1099.

49. Keusch GT: Opportunistic infections in colon carcinoma. Am J Clin Nutr 1974, 27(12):1481-1485.

50. Abdulamir AS, Hafidh RR, Abu Bakar F: The association of Streptococcus bovis/gallolyticus with colorectal tumors: the nature and the underlying mechanisms of its etiological role. J Exp Clin Cancer Res 2011, 30:11.

51. Zhan $P$, et al: Chlamydia pneumoniae infection and lung cancer risk: a meta-analysis. Eur J Cancer 2011, 47(5):742-747.

52. Kocazeybek B: Chronic Chlamydophila pneumoniae infection in lung cancer, a risk factor: a case-control study. J Med Microbiol 2003, 52(Pt 8):721-726.

53. Koyi $\mathrm{H}$, et al: An association between chronic infection with Chlamydia pneumoniae and lung cancer. A prospective 2-year study. APMIS 2001, 109(9):572-580.

54. Laurila $\mathrm{AL}$, et al: Serological evidence of an association between Chlamydia pneumoniae infection and lung cancer. Int J Cancer 1997, 74(1):31-34.

55. Littman AJ, et al: Chlamydia pneumoniae infection and risk of lung cancer. Cancer Epidemiol Biomarkers Prev 2004, 13(10):1624-1630.

56. Mager DL: Bacteria and cancer: cause, coincidence or cure? A review. J Transl Med 2006, 4:14

57. Decker WK, Safdar A: Bioimmunoadjuvants for the treatment of neoplastic and infectious disease: Coley's legacy revisited. Cytokine Growth Factor Rev 2009, 20(4):271-281

58. Hoption Cann SA, Van Netten JP, Van Netten C: Dr William Coley and tumour regression: a place in history or in the future. Postgrad Med J 2003, 79(938):672-80.

59. Ruckdeschel JC, et al: Postoperative empyema improves survival in lung cancer. Documentation and analysis of a natural experiment. $N$ Engl J Med 1972, 287(20):1013-1017.

60. Kapp JP: Microorganisms as antineoplastic agents in CNS tumors. Arch Neurol 1983, 40(10):637-642.

61. Bohman LE, et al: The survival impact of postoperative infection in patients with glioblastoma multiforme. Neurosurgery 2009, 64(5):828-834 discussion 834-5.

62. Wei $\mathrm{MQ}$, et al: Facultative or obligate anaerobic bacteria have the potential for multimodality therapy of solid tumours. Eur J Cancer 2007, 43(3):490-496.

63. Baban CK, et al: Bacteria as vectors for gene therapy of cancer. Bioeng Bugs 2010, 1(6):385-394.

64. Bermudes D, Low B, Pawelek J: Tumor-targeted Salmonella. Highly selective delivery vectors. Adv Exp Med Biol 2000, 465:57-63.

65. Sznol $M$, et al: Use of preferentially replicating bacteria for the treatment of cancer. J Clin Invest 2000, 105(8):1027-1030 
66. Berg RD, Garlington AW: Translocation of certain indigenous bacteria from the gastrointestinal tract to the mesenteric lymph nodes and other organs in a gnotobiotic mouse model. Infect Immun 1979, 23(2):403-411.

67. Balzan S, et al: Bacterial translocation: overview of mechanisms and clinical impact. J Gastroenterol Hepatol 2007, 22(4):464-471.

68. Cannon JP, et al: Pathogenic relevance of Lactobacillus: a retrospective review of over 200 cases. Eur J Clin Microbiol Infect Dis 2005, 24(1):31-40.

69. Penn RL, Maca RD, Berg RD: Increased translocation of bacteria from the gastrointestinal tracts of tumor-bearing mice. Infect Immun 1985, 47(3):793-798.

70. Cronin $\mathrm{M}$, et al: Orally administered bifidobacteria as vehicles for delivery of agents to systemic tumors. Mol Ther 2010, 18(7):1397-1407.

71. Berg RD: Translocation of enteric bacteria in health and disease. Curr Stud Hematol Blood Transfus 1992, 59:44-65.

72. Farrell JJ, et al: Variations of oral microbiota are associated with pancreatic diseases including pancreatic cancer. Gut 2012, 61(4):582-588.

73. Goldenberg RL, Culhane JF: Preterm birth and periodontal disease. N Engl J Med 2006, 355(18):1925-1927.

74. Iwai T: Periodontal bacteremia and various vascular diseases. J Periodontal Res 2009, 44(6):689-694.

75. Sakamoto $H$, et al: Isolation of bacteria from cervical lymph nodes in patients with oral cancer. Arch Oral Biol 1999, 44(10):789-793.

76. Sjostedt S, et al: Microbial colonization of tumors in relation to the upper gastrointestinal tract in patients with gastric carcinoma. Ann Surg 1988, 207(3):341-346.

77. Han YW, et al: Interactions between periodontal bacteria and human oral epithelial cells: Fusobacterium nucleatum adheres to and invades epithelial cells. Infect Immun 2000, 68(6):3140-3146.

78. Signat $B$, et al: Fusobacterium nucleatum in periodontal health and disease. Curr Issues Mol Biol 2011, 13(2):25-36.

79. Swidsinski A, et al: Acute appendicitis is characterised by local invasion with Fusobacterium nucleatum/necrophorum. Gut 2011, 60(1):34-40

80. Sears CL, Pardoll DM: Perspective: alpha-bugs, their microbial partners, and the link to colon cancer. J Infect Dis 2011, 203(3):306-311.

81. Strauss J, et al: Invasive potential of gut mucosa-derived Fusobacterium nucleatum positively correlates with IBD status of the host. Inflamm Bowel Dis 2011, 17(9):1971-1978.

82. Chaim W, Mazor M: Intraamniotic infection with fusobacteria. Arch Gynecol Obstet 1992, 251(1):1-7.

83. Hill GB: Preterm birth: associations with genital and possibly oral microflora. Ann Periodontol 1998, 3(1):222-232.

84. Carroll GC, Sebor RJ: Dental flossing and its relationship to transient bacteremia. J Periodontol 1980, 51(12):691-692.

85. Daly C, et al: Bacteraemia caused by periodontal probing. Aust Dent J 1997, 42(2):77-80.

86. Daly CG, et al: Bacteremia due to periodontal probing: a clinical and microbiological investigation. J Periodontol 2001, 72(2):210-214.

87. Han YW, et al: Fusobacterium nucleatum induces premature and term stillbirths in pregnant mice: implication of oral bacteria in preterm birth. Infect Immun 2004, 72(4):2272-2279.

88. Cronin $\mathrm{M}$, et al: High resolution in vivo bioluminescent imaging for the study of bacterial tumour targeting. PLOS One 2012, 7(1):e30940.

89. Tangney M, et al: Gene therapy for prostate cancer. Postgrad Med 2010, 122(3):166-180.

90. Tangney M: Gene therapy for cancer: dairy bacteria as delivery vectors. Discov Med 2010, 10(52):195-200.

91. van Pijkeren JP, et al: A novel Listeria monocytogenes-based DNA delivery system for cancer gene therapy. Hum Gene Ther 2010, 21(4):405-416.

92. Vassaux $G$, et al: Bacterial gene therapy strategies. J Pathol 2006, 208(2):290-298.

93. Loessner $\mathrm{H}$, Weiss $\mathrm{S}$ : Bacteria-mediated DNA transfer in gene therapy and vaccination. Expert Opin Biol Ther 2004, 4(2):157-168.

doi:10.1186/1750-9378-8-11

Cite this article as: Cummins and Tangney: Bacteria and tumours: causative agents or opportunistic inhabitants?. Infectious Agents and Cancer 2013 8:11.

\section{Submit your next manuscript to BioMed Central and take full advantage of:}

- Convenient online submission

- Thorough peer review

- No space constraints or color figure charges

- Immediate publication on acceptance

- Inclusion in PubMed, CAS, Scopus and Google Scholar

- Research which is freely available for redistribution 